\title{
Prevalence and predictors of post stroke depression among elderly stroke survivors
}

\author{
Prevalência e preditores de depressão pós-AVC em idosos sobreviventes de acidente \\ vascular cerebral
}

Emanuella Barros dos Santos' ${ }^{1}$ Rosalina Aparecida Partezani Rodrigues ${ }^{1}$, Octávio Marques Pontes-Neto²

\begin{abstract}
Objective: To identify the prevalence of post stroke depression (PSD) and their socio-demographic and clinical predictors among elderly stroke survivors after hospital discharge to home. Methods: In this cross-sectional study, 90 elderly stroke survivors were evaluated 14 days after hospital discharge with the following scales: National Institutes of Health Stroke Scale, Functional Independence Measure, and Geriatric Depression Scale - 15 items (GDS-15). PSD was defined as a score $>5$ on GDS-15. After univariate analyses, a multivariate logistic regression model was built to identify independent predictors of PSD. Results: Fourteen days after hospital discharge, $27.7 \%$ ( $95 \% \mathrm{Cl} 18.1$ to 37.2) of elderly stroke survivors had PSD. Functional dependence was the only independent predictor of PSD (OR: 1.04 95\%Cl: 1.01 to 1.09; $p=0.02$ ). Conclusion: After stroke, depressive symptoms are common among elderly survivors. The degree of functional dependency is the main predictor of PSD among elderly stroke patients in Brazil.
\end{abstract}

Keywords: stroke; depression; aged; activities of daily living.

\section{RESUMO}

Objetivos: Identificar a prevalência de depressão pós-AVC (DPAVC) e seus preditores sócio-demográficos e clínicos nos idosos sobreviventes do acidente vascular cerebral (AVC) após alta hospitalar para casa. Métodos: Nesse estudo transversal, 90 idosos sobreviventes do AVC foram avaliados 14 dias após alta hospitalar com as escalas a seguir: National Institutes of Health Stroke Scale, Medida da Independência Funcional (MIF), Escala de Depressão Geriátrica - 15 itens (EDG-15). DPAVC foi definida como escore $>5$ na EDG-15. Depois da análise univariada, a regressão logística multivariada foi construída para identificar os preditores independentes da DPAVC. Resultados: Quatorze dias após a alta hospitalar, 27,7\% (IC95\% = 18,1-37,2) dos idosos sobreviventes do AVC tinham DPAVC. A dependência funcional foi o único preditor independente da DPAVC (OR: $1.0495 \% \mathrm{Cl}$ : 1,01-1,09; $\mathrm{p}=0.02)$. Conclusão: Após um AVC, sintomas depressivos são frequentes entre os idosos sobreviventes. O grau de dependência funcional é o principal preditor da DPAVC neste pacientes no Brasil.

Palavras-chave: acidente vascular cerebral; depressão; idoso; atividades cotidianas.

Stroke is a major health problem among the elderly. In Brazil, it is a major cause of death in this population. In 2013, there were more than 80,000 deaths from stroke among people aged 60 years and over. ${ }^{1}$. Although still a major cause of mortality, the death rate from stroke has declined across the country in recent years². A decrease in stroke lethality along with the aging of our population and the delayed epidemiological transition to chronic non-infectious diseases leads to an increasing number of stroke survivors and years of life lost due to stroke related disability in the country3.

Stroke is one of the most common causes of disability among adults and elderly people in the world and can cause physical and mental problems ${ }^{4}$. Depression is a common psychological complication after stroke ${ }^{5}$. According to the Diagnostic and Statistical Manual of Mental Disorders V (DMS-V), post-stroke depression (PSD) is a mood disorder resulting from a medical condition and may be characterized by an episode of major depression or mood disorder with depressive symptoms ${ }^{6}$.

The estimated prevalence of depression among stroke survivors is $28 \%$ in the first month after stroke and $31 \%$ at any time up to five years after stroke ${ }^{5}$. Previous history of depression, the severity of neurological deficit, functional dependency and pre-stroke depression have been reported as predictive factors

1 Universidade de São Paulo, Escola de Enfermagem de Ribeirão Preto, Departamento de Enfermagem Geral e Especializada, Ribeirão Preto SP, Brasil;

${ }^{2}$ Universidade de São Paulo, Faculdade de Medicina de Ribeirão Preto, Departamento de Neurociências e Ciências do Comportamento, Ribeirão Preto SP, Brasil.

Correspondence: Rosalina Aparecida Partezani Rodrigues; Universidade de São Paulo, Escola de Enfermagem de Ribeirão Preto; Av. Bandeirantes, 3900; 14040-902, Ribeirão Preto SP, Brasil.E-mail: rosalina@eerp.usp.br

Conflict of interest: There is no conflict of interest to declare.

Support: CNPq (Conselho Nacional de Desenvolvimento Científico e Tecnológico. 482721/2013-8; 402388/2013-5) e FAPESP (Fundação de Apoio à Pesquisa de São Paulo. 2012/51725-2).

Received 16 December 2015; Accept 02 May 2016. 
of PSD in developed countries ${ }^{7}$. Some authors also report the relationship between post-stroke depression and sociodemographic characteristics (gender ${ }^{8,9}$, age ${ }^{10}$ ), but the results are still controversial and mainly from more developed countries ${ }^{7}$.

Due to socioeconomic and cultural differences between developed and developing countries, strokes of similar severity can cause different consequences among survivors living in those countries. In Brazil, data on psychosocial consequences of stroke are scarce. In a recent review of the scientific literature, we found very scarce data about the prevalence and predictors of PSD in elderly stroke survivors in Brazil.

The objectives of this study were to identify the prevalence of PSD and their socio-demographic (gender, age, marital status, education, income) and clinical (stroke subtype, comorbidities, neurological deficit and functional independence) predictors among elderly stroke survivors after hospital discharge to home.

\section{METHODS}

\section{Participants}

This cross-sectional study was conducted in the municipalities of the XIII Regional Department of Health of São Paulo state. The study population consisted of stroke survivors treated at the tertiary Emergency Unit of the Faculdade de Medicina de Ribeirão Preto (HCFMRP-USP), between January 2011 and January 2012, and therefore included in the Ribeirão Preto Stroke Registry (REAVER). The inclusion criteria were: (1) being aged 60 or over; (2) having a medical diagnosis of the first stroke event confirmed by Computed Tomography; (3) living within the district of the XIII Regional Health Department; (4) being able to communicate verbally; and (5) with preserved cognitive function. For the assessment of cognitive function, we used the Brazilian version of the Mini-Mental State Examination (MMSE) ${ }^{11}$. The cut-off points, adapted to the educational level of the Brazilian population, are 13 for illiterate subjects, 18 for those who studied between 1 and 8 years and 26 for those who studied more than 8 years ${ }^{11}$. Exclusion criteria were: (1) having a severe neurological comorbidity (tumor, brain damage resulting from traumatic brain injury); (2) living in an Institution for the Aged (IA), (3) having a diagnosis of subarachnoid hemorrhage and (4) aphasia. The final sample consisted of 90 elderly stroke survivors.

\section{Instruments}

To survey the demographic data we used a structured script containing the following variables: age (years), age group (younger elderly $\leq 79$ years, older elderly $\geq 80$ years), gender (female, male), education (years of formal education), monthly income (in Reais) and marital status (single, married, divorced/separated). The type of stroke (ischemic and hemorrhagic), length of hospitalization (days), and comorbidities were collected from the medical records.

To measure neurological deficit, we used the validated Brazilian version of the National Institute of Health Stroke Scale
$(\mathrm{NIHSS})^{12}$. The NIHSS provides a quantitative assessment of the neurological deficits associated with stroke, consisting of 11 items that assess the following areas: consciousness, horizontal eye movement, visual field test, facial palsy, muscle strength in the limbs, limb ataxia, sensitivity, speech and language. The total score ranges from 0 (no neurological deficit) to 42 points (greater neurological deficit). According to the NIHSS score, the stroke can be classified as mild $(<4)^{13}$, moderate $(\geq 4$ and $\leq 15)$ and severe ( $>15)$. The Brazilian version of this scale showed an intraclass correlation coefficient of $0.902(95 \% \mathrm{CI}=0.84-0.94)^{12}$.

Functional independence after stroke was evaluated using the Brazilian version of the Functional Independence Measure (FIM) ${ }^{14}$. This scale assesses the degree of care required for performing basic activities of daily living. It consists of 18 items that evaluate motor and cognitive activities, which are distributed across self-care, sphincter control, transportation, locomotion, communication and social cognition. The score for each item may vary from 1 (complete dependence) to 7 (completely independent). The score of the motor subscale varies between 13 and 91 points, and the cognitive subscale between 5 and 35 points. The total score ranges from 18 (lowest level of independence) to 126 points (highest level of independence). In the Brazilian version, FIM subscales had good correlation with test/retest reliability (Pearson: 0.91-0.98; CI: 0.91-0.98) and between two observers (Pearson: 0.87-0.98; CI: 0.87-0.98) ${ }^{14}$.

PSD was assessed using the Geriatric Depression Scale, 15 items (GDS-15).This scale was translated and validated in Brazil with test-retest ( $r h o=0.86, \mathrm{p}<0.001$ ), kappa coefficient 0.64 and good internal consistency (Croncbach $\alpha=0.81)^{15}$. The GDS-15 is a reduced version of the original scale, being composed of 15 items strongly associated with the diagnosis of depression with dichotomous responses (yes or no) to the questions. The rating scale ranges from 0 to 15 points and features the cut-off score $5 / 6$ (non-case/case). Scores lower than or equal to 5 on the GDS-15 indicate no clinically significant depressive symptoms. This cut-off point produced $90.9 \%$ sensitivity, and $64.5 \%$ specificity for diagnosis of major depression according to DSM-IV ${ }^{16}$.

\section{Procedures}

In order to identify those eligible for the study, electronic medical records were observed on a daily basis. After hospital discharge to go home we contacted the eligible subject by telephone to invite them to participate and to schedule the date for data collection if they were in agreement. Data was collected by a nurse trained to apply the instruments, via structured interviews in the subject's home 14 days after hospital discharge.

\section{Statistical analysis}

Data were analyzed using the Statistical Package for Social Sciences software (SPSS) for Windows, version 21.0. Descriptive statistics including mean, standard deviation, median, interquartile range, absolute and relative frequencies were used to summarize the characteristics of the participants and their answers on the instruments. To evaluate the association between PSD and categorical variables (gender, age, marital status), 
we used the chi-square test or Fisher's exact test, as appropriate. Independent t test was used to check whether there was a difference between depressive survivors and non-depressive survivors in terms of income, years of formal education, number of comorbidities and functional independence. Mann-Whitney test was used to compare depressive survivors and non-depressive survivors in terms of neurological deficits. Logistic regression was used to identify independent predictors of PSD. The level of significance was set at $\alpha<0.05$ (two-tailed).

The study followed the ethical precepts of the Brazilian National Health Council Resolution 196/1996 and was carried out after approval by the Research Ethics Committee of the Ribeirão Preto Medical School - USP, according to protocol number 10358/210 and CEP-FMRP/USP - 3577/2010. All participants were invited to participate and those who accepted signed the consent form.

\section{RESULTS}

Sociodemographic characteristics of 90 elderly stroke survivors are shown in Table 1. The mean age was $71.2 \pm 8.4$ years, ranging between 60 and 94 years. There was no difference between the mean age of men and women ( $p=0.225)$. Most married survivors $(77 \%)$ were male. The mean length of formal education was $3.3 \pm 3.6$ years, the mean monthly income was $R \$ 915.00 \pm 610.00$ and retirement (61.1\%) was the main source of income.

As for stroke subtype, $92.2 \%$ of survivors had suffered ischemic stroke. The average number of comorbidities was $2.44 \pm 1.35$. The two most common comorbidities were hypertension (86.7\%) and diabetes mellitus (37.8\%). Forty-six stroke survivors (51\%) had three or more comorbidities. Regarding length of hospitalization,

Table 1. Distribution of elderly stroke survivors, according to sociodemographic variables.

\begin{tabular}{|cc}
\hline Variables & $\mathrm{n}(\%)$ \\
\hline Gender & \\
\hline Female & $39(43.3)$ \\
\hline Male & $51(56.7)$ \\
\hline Age (years) & \\
$60-64$ & $23(25.6)$ \\
$65-69$ & $20(22.2)$ \\
$70-74$ & $17(18.9)$ \\
\hline $75-79$ & $11(12.2)$ \\
\hline 80 or more & $19(21.1)$ \\
Marrital status & \\
\hline Single & $6(6.7)$ \\
\hline Married & $48(53.3)$ \\
\hline Divorced/Separated & $36(40)$ \\
\hline Education (formal education in years) & \\
\hline None & $24(26.7)$ \\
\hline $1-4$ & $50(55.6)$ \\
\hline $5-8$ & $10(11.1)$ \\
\hline $9-12$ & $3(3.3)$ \\
\hline 13 or more & $3(3.3)$ \\
\hline
\end{tabular}

the mean was $8.37 \pm 8$ days and $52.2 \%$ remained $1-5$ days in the hospital. The mean length of hospitalization for the older elderly was $11.42 \pm 10.3$ days and $7.55 \pm 7.2$ days for the younger elderly, but this difference was not statistically significant ( $p=0.063$ ).

The median and interquartile range of the NIHSS variables, FIM total, motor FIM, cognitive FIM of elderly stroke survivors were respectively 2 (0-6), 115 (82.75-121), 80 (54-87.75), 34 (32.25-35). As for stroke severity, 68.9\% suffered mild stroke, $27.8 \%$ moderate and $3.3 \%$ severe. According to the FIM, $70 \%$ of stroke survivors had modified independence to carry out activities of daily living.

The prevalence ofPSD in the elderly stroke survivors was $27.7 \%$ (95\%CI: 18.1 to 37.2). An analysis comparing depressive survivors and non-depressive survivors showed no difference between the groups in terms of mean length of formal education $(p=0.54)$, income $(p=0.9)$ and number of comorbidities $(p=0.4)$. The other bivariate analyses are presented in Tables 2 and 3. When comparing the depressive and non depressive elderly stroke survivors, we found a significant difference for functional independence. Elderly stroke survivors with PSD showed greater functional dependence and more neurological deficits when compared to non-depressive elderly survivors, as shown in Table 3.

According to the logistic regression analysis, functional dependence, measured by FIM, was the only independent predictor of PSD (Table 4).

Table 2. Distribution of the depressive and non-depressive elderly stroke survivors according to gender, age, marital status, type of stroke, diabetes mellitus and hypertension.

\begin{tabular}{|c|c|c|c|}
\hline \multirow{3}{*}{ Variable } & \multicolumn{2}{|c|}{ Depression } & \multirow{3}{*}{$\mathrm{p}$-value } \\
\hline & Yes & No & \\
\hline & n (\%) & $\mathrm{n}(\%)$ & \\
\hline \multicolumn{4}{|l|}{ Gender } \\
\hline Male & $13(25.5)$ & $38(74.5)$ & \multirow{2}{*}{0.4} \\
\hline Female & $12(30.8)$ & $27(69.2)$ & \\
\hline \multicolumn{4}{|l|}{ Age group } \\
\hline Younger elderly* & $17(23.9)$ & $54(76.1)$ & \multirow{2}{*}{0.3} \\
\hline Older elderly** & $8(42.1)$ & $11(57.9)$ & \\
\hline \multicolumn{4}{|l|}{ Marital status } \\
\hline With partner & $12(25)$ & $36(75)$ & \multirow{2}{*}{0.39} \\
\hline Without partner & $13(31)$ & $29(69)$ & \\
\hline \multicolumn{4}{|l|}{ Stroke subtype } \\
\hline Ischemic stroke & $22(26.5)$ & $61(73.5)$ & \multirow{2}{*}{0.37} \\
\hline Hemorrhagic stroke & $3(42.9)$ & $4(57.1)$ & \\
\hline \multicolumn{4}{|l|}{ Diabetes mellitus } \\
\hline Yes & $12(35.3)$ & $22(64.7)$ & \multirow{2}{*}{0.14} \\
\hline No & $13(23.2)$ & $43(76.8)$ & \\
\hline \multicolumn{4}{|l|}{ Hypertension } \\
\hline Yes & $20(25.6)$ & $58(74.4)$ & \multirow{2}{*}{0.2} \\
\hline No & $5(41.6)$ & $7(58.4)$ & \\
\hline
\end{tabular}

*Young elderly = between $60-79$ years; ${ }^{\star *}$ Older elderly $=$ age over 80 years. 
Table 3. Distribution of the functional independence measure (FIM) scores (total, motor and cognitive) and National Institutes of Health Stroke scale (NIHSS) of elderly stroke survivors according to depression.

\begin{tabular}{lccc}
\hline \multirow{2}{*}{ Variables } & \multicolumn{2}{c}{ Depression } & \multirow{2}{*}{-value } \\
\cline { 2 - 3 } & Yes & No & \\
\hline FIM total, mean (SD) & $89.8(24.1)$ & $107.7(22.5)$ & 0.002 \\
Motor FIM, mean (SD) & $57.6(23.3)$ & $74.3(21.5)$ & 0.002 \\
Cognitive FIM, mean (SD) & $32.2(2.9)$ & $33.4(2.1)$ & 0.028 \\
NIHSS, median (IR) & $3(2-9)$ & $2(0-4)$ & 0.022 \\
\hline
\end{tabular}

SD: standard deviation; IR: interquatile range.

\section{DISCUSSION}

Depression is a common complication after stroke and its prevalence varies according to time $\mathrm{e}^{5}$. The prevalence of PSD in the acute phase observed in this study was similar to that found in studies conducted in developed countries ${ }^{5,17}$ and developing countries $^{8}$. In a prospective study conducted in China on stroke survivors treated at a teaching hospital, the prevalence of PSD, as measured by the Hamilton Depression Rating Scale, was $27.4 \%$ two weeks after stroke. ${ }^{8}$. Similarly, in Finland, 27\% of survivors of the first ischemic stroke event had PSD two weeks after stroke, according to the Beck Depression Inventory ${ }^{17}$. In contrast, a study conducted in Brazil ${ }^{9}$ and another in Hong Kong ${ }^{18}$ reported prevalences of $41.7 \%$ and $68 \%$ of depression among stroke survivors, respectively. These results should be interpreted cautiously for several reasons. Although the Brazilian study used the same rating scale and cut-off point for depression, the survivors were recruited from a rehabilitation hospital and $57 \%$ of these were assessed 12 months after stroke'. Moreover, as in the study from Hong Kong ${ }^{18}$, the participants of the Brazilian study ${ }^{9}$ were more dependent for activities of daily living than the participants of this study, which may have contributed to the increased prevalence of depressive symptoms. Despite the differences in prevalence that may occur between studies due to changes in diagnostic criteria, selection of patients and time since the stroke, the prevalence of PSD in our study is consistent with the results of a systematic review of observational studies where they found a prevalence of $28 \%$ (95\%CI, $23 \%-33 \%$ ) of PSD in survivors within one month after the stroke.

The origin of PSD is complex and presents a multifactorial aetiology with biological and/or psychosocial components ${ }^{19,20}$. Some studies found a higher prevalence of PSD among wom$\mathrm{en}^{8-9}$, survivors with fewer years of education ${ }^{9}$ and the older elderly $^{10}$. The results for the relationship between post-stroke depression and socio-demographic characteristics are contraditory? In this study, there was no relationship between the sociodemographic characteristics of survivors and PSD. Our findings corroborate a systematic review of observational studies, in which there was no evidence that socio-demographic characteristics are predictors of $\mathrm{PSD}^{7}$.
Table 4. Multivariate logistic regression for predictors of post stroke depression.

\begin{tabular}{lccc}
\hline Variables & OR & $95 \% \mathrm{Cl}$ & $\mathrm{p}$-value \\
\hline Age & 0.98 & $0.91-1.05$ & 0.65 \\
Gender & 1.00 & $0.34-2.91$ & 0.99 \\
FIM score & 1.04 & $1.01-1.09$ & 0.02 \\
NIHSS score & 1.11 & $0.90-1.35$ & 0.28 \\
\hline
\end{tabular}

FIM: functional independence measure; NIHSS: National Institutes of Health Stroke scale; OR: odds ratio; Cl: confidence interval.

Neither stroke subtypes nor comorbidities were related with PSD in our study. The small number of survivors with hemorrhagic stroke, in this study, may have interfered in the stroke subtype ratio analysis with PSD. However, it is believed that the stroke etiology and topography itself is not sufficient to explain the occurrence of PSD ${ }^{21}$. Other factors such as history of previous depression and dependency in activities of daily living seem to overcome the topography and etiology of stroke in predicting depression ${ }^{7,21}$.

The importance of dependence in activities of daily living in the prediction of PSD is well established in the literature ${ }^{7,21,22}$. However, it is also likely that some degree of functional dependence may also be a consequence of depression ${ }^{7}$. In a systematic review of observational studies, stroke survivors with depression had poorer prognoses of functional independence compared to those without depression ${ }^{7}$. Regardless of the causal relationship between these two conditions, the current study supports a strong association between depression and functional dependence in elderly stroke patients in Brazil ${ }^{23}$.

Elderly survivors deserve greater attention from health professionals in screening for PSD for two reasons. First, the prevalence of depression in this population is high and ranges between $0.9 \%$ and $42 \%^{24}$. The history of previous depression is a risk factor for the occurrence of post-stroke depression $^{7}$. In addition, age is an inverse predictor of post-stroke functional independence ${ }^{25}$ and lower functional dependence is related to $\mathrm{PSD}^{7}$. Thus, it is suggested that the elderly have a greater risk of developing depression after stroke.

It is noteworthy that our study has some limitations. The small sample size generates imprecision in some estimates. We suggest that further studies should be conducted with larger samples in developing countries. Stroke survivors with aphasia or cognitive impairment were excluded from the study, which prevents the generalization of the results for these populations. Another limitation was the missing data about the use of antidepressive medications and previous history of depression in the sample that could have influenced the results.

In conclusion, we found that depressive symptoms are common among elderly stroke survivors. In those patients, the degree of functional dependency was the main independent predictor of PSD in our sample of elderly stroke patients in Brazil. Adequate screening, diagnosis and treatment of depression in elderly patients with stroke may have a dramatic impact on their functional outcome. 


\section{References}

1. Ministério da Saúde (BR). DATASUS. Mortalidade: Brasil: Dados preliminares. Brasília, DF: Ministério da Saúde; 2013 [cited 2015 Mar 2]. Available from: http://tabnet.datasus.gov. br/cgi/tabcgi.exe?sim/cnv/pobt10uf.def

2. Lotufo PA, Goulart AC, Fernandes TG, Benseñor IM. A reappraisal of stroke mortality trends in Brazil (1979-2009). Int J Stroke. 2013;8(3):155-63. doi:10.1111/j.1747-4949.2011.00757.x

3. Feigin VL, Forouzanfar MH, Krishnamurthi R, Mensah GA, Connor $\mathrm{M}$, Bennett DA et al. Global and regional burden of stroke during 1990-2010: findings from the Global Burden of Disease Study 2010. Lancet. 2014;383(9913):245-54. doi:10.1016/S0140-6736(13)61953-4

4. Murray CJ, Vos T, Lozano R, Naghavi M, Flaxman AD, Michaud C et al. Disability-adjusted life years (DALYs) for 291 diseases and injuries in 21 regions, 1990-2010: a systematic analysis for the Global Burden of Disease Study 2010. Lancet. 2012;380(9859):2197-223. doi:10.1016/S0140-6736(12)61689-4

5. Hackett ML, Pickles K. Part I: frequency of depression after stroke: an updated systematic review and meta-analysis of observational studies. Int J Stroke. 2014;9(8):1017-25. doi:10.1111/ijs.12357

6. American Psychiatric Association. Diagnostic and statistical manual of mental disorders., 5th ed. Arlington: American Psychiatric Association; 2013.

7. Kutlubaev MA, Hackett ML. Part II: predictors of depression after stroke and impact of depression on stroke outcome: an updated systematic review of observational studies. Int J Stroke. 2014;9(8):1026-36. doi:10.1111/ijs.12356

8. Zhang WN, Pan YH, Wang XY, Zhao Y. A prospective study of the incidence and correlated factors of post-stroke depression in China. PLoS One. 2013;8(11):e78981. doi:10.1371/journal.pone.0078981

9. Carod-Artal FJ, Ferreira Coral L, Trizotto DS, Menezes Moreira C. Poststroke depression: prevalence and determinants in Brazilian stroke patients. Cerebrovasc Dis. 2009;28(2):157-65. doi:10.1159/000226114

10. Glamcevski MT 2nd, Pierson J. Prevalence of and factors associated with poststroke depression: a Malaysian study. J Stroke Cerebrovasc Dis. 2005;14(4):157-61. doi:10.1016/j.jstrokecerebrovasdis.2005.03.006

11. Bertolucci PH, Brucki SM, Campacci SR, Juliano Y. [The Mini-Mental State Examination in a general population: impact of educational status]. Arq Neuropsiquiatr. 1994;52(1):1-7. Portuguese. doi:10.1590/S0004-282X1994000100001

12. Cincura C, Pontes-Neto OM, Neville IS, Mendes HF, Menezes DF, Mariano DC et al. Validation of the National Institutes of Health Stroke scale, modified rankin scale and Barthel index in Brazil: the role of cultural adaptation and structured interviewing. Cerebrovas Dis. 2009;27(2):119-22. doi:10.1159/000177918
13. Fischer U, Baumgartner A, Arnold M, Nedeltchev K, Gralla J, De Marchis GM et al. What is a minor stroke? Stroke. 2010;41(4):661-6. doi:10.1161/STROKEAHA.109.572883

14. Riberto M, Miyazaki MH, Filho DJ, Sakamoto H, Battistella LR. Reprodutibilidade da versão brasileira da medida de independência funcional. Acta Fisiatr. 2001;8(1):45-52.

15. Almeida OP, Almeida SA. Confiabilidade da versão brasileira da escala de depressão em geriatria (GDS) versão reduzida. Arq Neuropsiquiatr. 1999;57(2B):421-6. doi:10.1590/S0004-282X1999000300013

16. Almeida OP, Almeida SA. Short versions of the geriatric depression scale: a study of their validity for the diagnosis of a major depressive episode according to ICD-10 and DSM-IV. Int J Geriatr Psychiatry. 1999;14(10):858-65. doi:10.1002/(SICI)1099-1166(199910)14:10<858::AID-GPS35>3.0.CO;2-8

17. Berg A, Palomäki H, Lehtihalmes M, Lönnqvist J, Kaste M. Poststroke depression in acute phase after stroke. Cerebrovasc Dis. 2001;12(1):14-20. doi: 10.1159/000047675

18. Lam SC, Lee LY, To KW. Depressive symptoms among community-dwelling, post-stroke elders in Hong Kong. Int Nurs Rev. 2010;57(2):269-73. doi:10.1111/j.1466-7657.2009.00789.x

19. Dafer RM, Rao M, Shareef A, Sharma A. Poststroke depression. Top Stroke Rehabil. 2008;15(1):13-21. doi:10.1310/tsr1501-13

20. Kouwenhoven SE, Kirkevold M, Engedal K, Kim HS. Depression in acute stroke: prevalence, dominant symptoms and associated factors: a systematic literature review. Disabil Rehabil. 2011;33(7):539-556. doi:10.3109/09638288.2010.505997

21. Allan LM, Rowan EN, Thomas AJ, Polvikoski TM, O’Brien JT, Kalaria RN. Long-term incidence of depression and predictors of depressive symptoms in older stroke survivors. Br J Psychiatry. 2013;203(6):453-60. doi:10.1192/bjp.bp.113.128355

22. Haghgoo HA, Pazuki ES, Hosseini AS, Rassafiani M. Depression, activities of daily living and quality of life in patients with stroke. J Neurol Sci. 2013;328(1-2):87-91. doi:10.1016/j.jns.2013.02.027

23. Brown C, Hasson H, Thyselius V, Almborg AH. Post-stroke depression and functional independence: a conundrum. Acta Neurol Scand. 2012;126(1):45-51. doi:10.1111/j.1600-0404.2011.01595.x

24. Djernes JK. Prevalence and predictors of depression in populations of elderly: a review. Acta Psychiatr Scand. 2006;113(5):372-87. doi:10.1111/j.1600-0447.2006.00770.x

25. Knoflach M, Matosevic B, Rücker M, Furtner M, Mair A, Wille G et al. Functional recovery after ischemic stroke--a matter of age: data from the Austrian Stroke Unit Registry. Neurology. 2012;78(4):279-85. doi:10.1212/WNL.0b013e31824367ab 